\title{
Diensthabende
}

\section{Medizin befreit!}

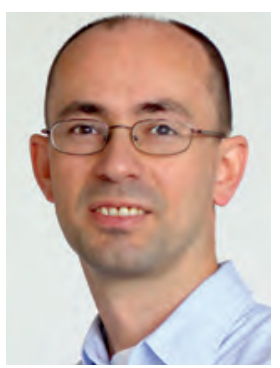

Dieses Studium hat es in sich: sechs Jahre dicht gepackter Stoff, saftige Prüfungen - und danach ein Job, der einen an Grenzen bringt. Trotzdem wollen Jahr für Jahr Zehntausende diesen Weg gehen. Warum eigentlich? Diese Frage stellt man vielleicht am besten denen, die bereits am Ziel sind. Deshalb haben wir junge Ärzte gefragt: Warum habt ihr diesen Beruf gewählt? Und warum seid ihr nach wie vor davon überzeugt, dass das eine gute Idee war (S. 22)? Was uns verblüffte: Keiner der Befragten nannte denselben Grund - doch jeder für sich taugt bereits als Argument, den Arztberuf zu ergreifen. Am nächsten liegt mir, was Denis Gümbel aus Greifswald geantwortet hat: „Für Ärzte gibt es keine Grenzen. Sie werden weltweit gebraucht." Damit hat er recht: Schon im Studium kann man per Auslandsfamulatur fast jede Ecke der Welt erkunden. Später kann man sich in vielen ลändern dieser Erde eine Existenz aufbauen. Den einen zieht es zum Beispiel nach Dubai, den anderen eher in seinen Kiez aus Kindertagen. Kurz: Als Arzt leistet man viel - aber man hat sein Leben selbst in der Hand! Gibt es Schöneres?

Herzlichst, euer Dieter Schmid
Fan werden unter: www.facebook.de/viamedici

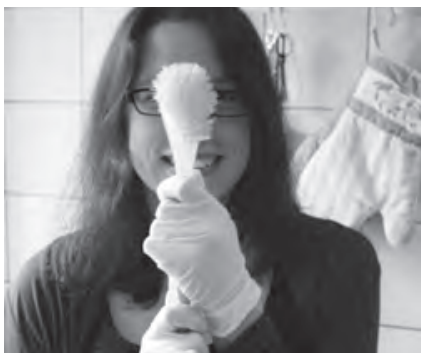

Tanja Peschel

hat für dieses Heft die Bewohner von Mediziner-WGs interviewt und dabei sehr viel Spaß gehabt. Jetzt freut sie sich, die Tipps aus ihrem Artikel auch in ihrer eigenen WG in die Tat umzusetzen - nicht nur, was den dort ewig drohenden Spülberg anbelangt (Seite 12).

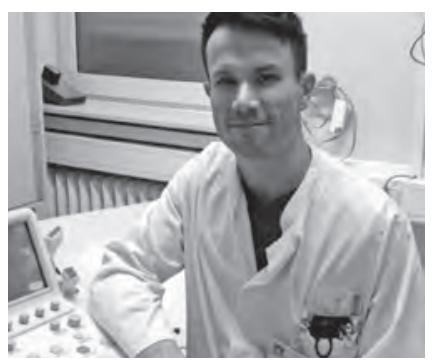

Dr. Oliver Knieps

hat uns eine Kasuistik über den Notfall Lungenembolie geschrieben - dabei ist er kürzlich selbst wegen eines entzündeten Weisheitszahnes zu einem ebensolchen geworden. Doch er hat beides gut überstanden: Der Artikel ist in diesem Heft - und der Zahn auf seinem Nachttisch (Seite 40).

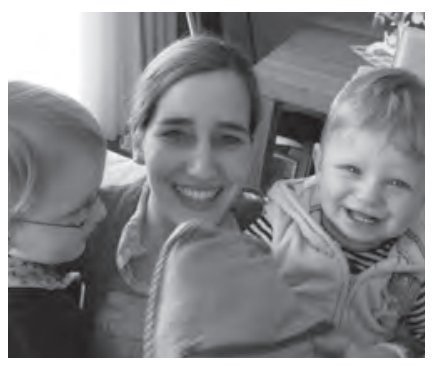

Verena Lucia Hagmann hat als Medizinjournalistin in puncto Nadelstichverletzungen zwar nichts zu befürchten. Aus ihrer Zeit als Assistenzärztin erinnert sie sich aber noch gut an den ein oder anderen unfreiwilligen „Piks“. Für dieses Heft hat die Zweifachmama recherchiert, was im Fall der Fälle zu tun ist (S. 39). 